Meta

Journal des traducteurs

Translators' Journal

\title{
Affixation and Compounding in New Words in Primarily American English
}

\section{Garland Cannon}

Volume 24, numéro 3, septembre 1979

URI : https://id.erudit.org/iderudit/002198ar

DOI : https://doi.org/10.7202/002198ar

Aller au sommaire du numéro

Éditeur(s)

Les Presses de l'Université de Montréal

ISSN

0026-0452 (imprimé)

1492-1421 (numérique)

Découvrir la revue

Citer cet article

Cannon, G. (1979). Affixation and Compounding in New Words in Primarily

American English. Meta, 24(3), 326-335. https://doi.org/10.7202/002198ar d'utilisation que vous pouvez consulter en ligne.

https://apropos.erudit.org/fr/usagers/politique-dutilisation/ 


\section{Affixation and Compounding in New Words in Primarily American English*}

In recent years there have been several major published collections of new words and meanings, apart from the continuing fascicles of the Linguistic Atlas of the United States and Canada and preparations for the Dictionary of American Regional English. In 1972 and 1976 there were the Supplements of the OED covering the letters $A-N$. In 1973 there was The Barnhart Dictionary of New English since 1963, which advertised « 5000 or so new entries and meanings 》. Meanwhile, Merriam-Webster was adding Addenda Sections at five-year intervals after appearance of Webster's Third New International Dictionary (W3, 1961). The 1966 one had 1182 main entries : the 1971 one, 2547 , with some deletions of ephemeral new meanings and words. Then in 1976 there was 6000 Words, containing 4881 main entries and 1331 run-ons, run-ins, and inflected forms.

Though there are no dates even for the rather generous number of citations, so that 6000 Words cannot be a direct guide to historical usage like Barnhart, its data are an index to the proportions and kinds of word formation that has been going on mainly since $1961^{I}$. Inasmuch as affixation and compounding account for the bulk of the new words, in contrast to the $5 \%$ represented by borrowing, we will study the syntactic aspects of the 2 processes, with appropriate checks in Barnhart and the OED Supplements. The results will shed light on the dynamic nature of Present-Day English, the general processes by which words are formed, and questions of lexicography and dialectology which confront publishers of major dictionaries.

We will first consider the relevant 65 items in the 1966 Addenda which are omitted from 6000 Words, since these can hardly be included in the data underpinning this paper. Actually, the 16 proper nouns of nationality like Angolan, consisting of Noun + Suffix, have been incorporated into the body of the 1971 reprint of W3. Sub-Saharan has a prefix, and Gaussian plane and ruly English are compounds. All 19 proper-noun derivatives contain at least one

* Paper read at the 5th International Congress of Applied Linguistics, August 1978, Montréal.

1. See Garland Cannon, \& Statistical Etymologies of New Words in American English 》, Journal of English Linguistics, 12 (1978), 12-18. Also, see Cannon and Beatrice Mendez Egle, \& New Borrowings in English », forthcoming in American Speech. 
affix and at least one free form in straightforward combination. Next, there are 3 derivations of the type gluconeogenic, consisting of bound forms. Another 30 derivations have a free form and usually just one prefix or suffix. For example, the 6 prefixed nouns are typified by subtopic; the 5 adjectives, by multination (which was replaced by multinational); and the verb depicture. The 11 suffixed nouns are derived through 2 occurrences each of $-e r$ as in waterskier, -ism as in polemicism, and -ing as in metalsmithing, plus 5 other common suffixes. The 6 suffixed adjectives employ 5 different derivational suffixes like -less as in spinless, and -ed in tenured. The adverb is ambulatorily. A tabulation of all these derivational items reveals 10 affixes to be the most common : 3 sub-and 2 multiand non-; $10-a n, 3-e r$ and -ian, and 4 suffixes with 2 occurrences. There are 13 noun compounds, of which 2 are syntactically ambiguous Adjective + Noun types like exotic fuel. The rest are Noun + Noun like insert sentence except in overfatigue.

Of these 65 Addenda items, Barnhart includes only cosmonette, cushioncraft and hovercraft, OED includes antistatic, 1938 ; exotic fuel, 1970 ; extremal, adj. 1432 , n. 1901 ; gluconeogenic, n.d. ; hovercraft, 1961 ; misallocation, 1950 ; multiparty, 1909 ; and 5 of the proper nouns of nationality dating back to 1804 (Bechuana). Of the 14 additional relevant items in the 1971 Addenda which do not appear in 6000 Words, Barnhart contains 5 , including the variant fertility drug instead of Webster's fertility pill. OED gives Afro-Asian, 1955 Newsweek; aquaplaning, 1914 ; and myofibrillar, 1927. One of the 14, Scientology, is composed purely of bound forms. There are also proper-noun derivatives, 5 compounds mostly like boilerplate, and 6 affixed nouns, including 4 scientific items like genoplasm and the inflected aquaplaning and baggies.

There are 246 items derived from proper nouns in 6000 Words, most of which ultimately involved affixation and / or compounding ${ }^{2}$. We will arbitrarily exclude what might be called preformed compounds like Yellow Pages and Peck's bad boy, the constituents of which George Wilbur Peck put together as his title. There are 58 items composed of a proper noun and one or more nonmedial affixes. Of the 36 suffixed nouns, the most common suffixes are 7 -ism as in Uncle Tomism, 7 -an as in Biafran but also in the biological pogonophoran, and 4 -in as in cephalosporin. The 20 suffixed adjectives contain 12 occurrences of -ian, wich is so productive that Barnhart gives it a main entry and lists 6 of the same items as in Skinnerian. There are also $3-a n$ as in Chomskian and 3 -esque as in Kafkaesque. The 2 prefixed items are neo-Dada and destalinization.

We find 30 occurrences of Proper Noun + Suffix + Word, of which 17 have the possessive form of the person's name as in Parkinson's Law. There are 5 -ian and 4 -an (Cartesian plane and American dream). We find 87 compounds without suffixes, all but 7 of the 73 nouns consisting of Name + Noun as in Caesar salad and Jesus freak. The 7 are of the type Sapir-Whorf hypothesis. The most common nouns are 8 ware as in Chien ware and 6 effect as in Gunn effect. Nouns like law, model, theory, and principle as in Peter Principle occur only

2. See Cannon, New Proper-Noun Derivatives in American English», Names, 25 (1977), 213-20. 
once each. There are 14 compounds of the type Word + Name. Except for the adjective off off-Broadway, all are nouns, 7 naming an entree like chicken Kiev.

As blends are a primarily phonological compound, with clipping of the initial word and aphaeresis of the terminal word, we will not treat the 35 blends. The affixation and/or compounding built upon abbreviations and initialisms perhaps falls within our purview. There are 22 items constructed from an abbreviation and a word, usually of the type $P$ Marker. We also find a compound $(C$-reactive protein) and a prefix (non-U). There are 6 \& and items as in $C$ and $W$ (country and western), the currency of which is indicated by Barnhart's including 5 of them (OED lists none). We find 6 initialisms with affixes, 4 of the type DNase and only poly 1 . poly $C$ with a prefix. There are 6 compounds like $T V$ dinner and 5 like transfer $R N A ; 3$ items have an initial abbreviation as in $s R N A$. Syntactic classification of words like bemegride are a lexicographer's nightmare. It does not abide by the strict rules of the International Scientific Vocabulary (ISV), yet is derivationally clear (beta $e$ thyl methyl glutaric imide).

Before we analyze the 1443 derivations and 1365 compounds which comprise the heart of this paper, the frequency of key affixes and combining forms might be noted. Some were so productive that the editors gave them main entries : anatomico-, atto-, femto-, millimicro-, tera-, ventriculo-, vesico-, manship, -on, -tene, -tuple, -ville, and -voltine. Anti- occurs 82 times, in traditional items like antibusing and in a productive new meaning as in antielectron that Barnhart places in a main entry. Next we find 44 micro-, 43 non-, 40 de-, 27 bio-, 21 pre-, and 18 multi-. There are also

15 cyto-, hydro-, immuno-, photo-, poly-

14 electro-, neuro-, para-, psyche-, re-

13 co-, hyper-, sub-

12 super-

11 cryo-, mini-

10 auto-, bi-, intra-, over-

9 counter-, mega-

8 inter-, magneto-, trans-, tri-

7 exo-, extra-, mono-, phosph-, phyto-, topo-, ultra-

6 astro-, chemo-, kilo-, peri-, retro-, semi-, thermo-

5 aero-, allo-, apo-, dis-, eco-, macro-, nucleo-, tele-, tetra-, turbo-

Lacking computer time, we have tabulated only the suffixes in items having one free form. For the noun suffixes we find $21-i s m, 19-e r, 17-y$ and -ing, 15 -ation and -ic(s), 14 -ist, 11 -ity, 10 -ase and -in, 8 -or, 7 -on and $-s$, and 8 others with at least 3 occurrences. The key adjective suffixes are $26-i c, 14-e d$, $13-a l, 9$-able, $7-y, 6$-less, and 5 others with at least 2 occurrences. Two free forms serve as terminals, viz., -ass as in smartass and -in as in teach-in, which are so productive that they are given main entries as new combining forms. 
There are 289 items composed of bound forms. Most have one initial and one terminal, relating mainly to science and technology. Their general syntactic simplicity would lead one to speculate rightly that at least the simpler items are not in the ISV. Thus we find allosteric and the linguistic basilect, with a few analogized items like monokini (cf. the folk etymology bi--kini) and trimaran (cf. cata-). Even some ISV items are composed of 2 clear morphemes as in baryon (bary- -on). There are a few new Adjective + Noun pairs like hydronic hydronics, where the subentry hydronically completes the set. The bulk of these 289 items are nouns, with some adjectives and 2 almost self-defining verbs (deuterate and sonicate). The adjective xenic is an interesting item created from a combining form and a suffix. Perhaps the most complicated «bound * item is cyproheptadine (cyclic propyl hepta-piperidine), which involves considerable clipping.

Another 1154 derivations consist of one free form and at least one affix. These can be divided into 704 nouns ( 456 prefixed and 248 suffixed forms), 353 adjectives (261 prefixed and 92 suffixed), 69 verbs (52 prefixed and 17 suffixed), 25 mixed-affix items, and 3 adverbs - countably, piecewise, and unitarily. Eighteen of the combinations are Prefix + Word + Suffix structures, typified by the noun oxotremorine, where tremor is medial. The analysis is not always straightforward. Thus disambiguate, the only verb of this group, cannot be described as Prefix + Word, like depollute, since there is no *ambiguate. The -ate must be analyzed as a suffix, leaving a medial root that is not a true free form. Nor can disinsection be persuasively analyzed as a prefixing of *insection, though it is the semantic antonym. Most of these 18 items deal with science. So do the Bound Forms + Word items as in neurohemal organ, which, with suitable dated citations, could well be considered a compounding of an earlier initial word constructed from 2 bound forms + organ.

Some nouns formed by simple affixation pose similar etymological problems. For example, the development of items like bachelorette and ranchette might suggest that couchette «sleeping compartment on a European train 》 is another -ette, since the compartment is a couch during the day. But the etymology is given as « dim. of couche bed, fr. MF ; Barnhart assigns it to French, giving a 1964 citation with a French-train context that would seem to resolve the matter. Psychopharmaceutical, which has a 1969 citation in Barnhart, is incompletely etymologized in both dictionaries. Was there a functionally shifted noun pharmaceutical, to which psycho- was prefixed; or was there an original adjective psychopharmaceutical, of which we have no record, which functionally shifted? Neither dictionary indicates a shift, though the -ic form suggests it. The sequence is important in our understanding the process of word formation. Audiovisuals was clearly shifted from an earlier adjective and pluralized. Teeny, which takes a plural, is not etymologized because the derivation is equally clear, teenager was clipped and then took $-y$, to become homonymous with the existing adjective. Just a zing was suffixed to form zinger (and zingy), bop was suffixed to give bopper. Compounding then produced teenybopper, which is not pluralized as *teeniesbopper. 
Other sets of nouns have come into American English similarly, in chronologies which we can sometimes reconstruct with the help of Barnhart's dates. Barnhart specifies that the adjective hip came into the language in the 1950's, though it does not appear in W3. Barnhart's first citation for the slang noun hip and its verb is 1970. Webster's entered hip as a new noun meaning in 1971, never listing the verb. Evidently the earlier adjective functionally shifted. Meanwhile, hippie was formed by a suffix, Barnhart citing 1968 usages of the noun and the adjective (which Webster's does not list). This noun was next suffixed to give hippiedom by 1971, a form not in Barnhart, which supplies 2 other derivations, hippiness in 1968 and hippyism in 1970. Barnhart gives a 1971 citation for hipdom, described as an alternate of hippiedom. For Webster's the original form was still productive, giving hipness by 1971. A parallel step would seem to have produced a new synonym for hipness by 1976, hipsterism \& the way of life characteristic of hipsters $\%$. Thus Webster's found that the earlier, dated hipster had been dusted off to serve as a root, unlike Barnhart, which cites only hippyism as the perhaps predictable form in 1970.

Some new nouns provide grammatical and other information. The appearance of parietal and point in the 1971 Addendum, which gave an $-s$ plural, would seem to confirm that these items were soon used only in the plural, as listed in both 6000 Words and Barnhart, which disturbingly provides 1967 and 1968 citations, respectively. We find another aspect of number in periapsis, which reinforces the Greek plural apsides (and the adjective apsidal) that is already in English. The 1971 entry of aposelene provides an original Greek variant to the also-new apolune (Barnhart, 1969), a prefixed originally Latin root that receives the definition. Another interesting noun is noncandidate, which first appeared in the 1966 Addendum but was omitted in 1971, reappearing in 1976 without editorial indication of whether the omission was accidental or reflective of a temporarily dubious status.

There is a huge diversity of free forms in the 353 adjectives formed by addition of an affix. Each one is different in those which are derived by suffixation, but some which join with a prefix are productive :

$\begin{array}{ll}\text { active } & \text { (pro-, psycho-, vaso-) } \\ \text { electric } & \text { (acousto-, myo-, turbo-) } \\ \text { functional } & \text { (di-, mono-, tetra-, tri-) } \\ \text { nuclear } & \text { (anti-, chemo-, non-, peri-) } \\ \text { sensory } & \text { (chemo-, inter-, multi-, neuro-) } \\ \text { sexual } & \text { (mono-, para-, uni-) } \\ \text { vascular } & \text { (intra-, micro-, reno-) }\end{array}$

The adjectives range from monosyllabic combinations like non- + green and bra + -less to the syllabically complex histophysiological. Only antiauthoritarian, cardioaccelerator, immunohistochemical, and myeloproliferative also have 8 sylla- 
bles. Only 5 items like polyunsaturated are composed of a disyllabic prefix and a free form of 5 syllables. The 353 adjectives average almost 4 syllables each.

Of the 10 with at least 7 syllables, only polyunsaturated appears in Barnhart (1967). Only 8 of the many \& anti- items appear, though one could shed light on recent American social and political history by listing and dating words like -black, -busing, -litter, -noise, -obscenity, and -war. Nor does Barnhart list bidialectal, sociolinguistic, or biunique, of the recent linguistic terms. The latter is one of several potentially semantically unique items, non- being the most productive prefix in combining with words like empty, identical, and negative.

Some adjectives pose etymological problems like those observed in the derived nouns. There is no question about words like biodegradable, which derives from the prefixing of an adjective. But as some items were apparently created by the prefixing or suffixing of a noun, we often cannot know whether the derivation was first a noun that then functionally shifted to an adjective, the reverse of this process, or a roughly simultaneous development of both forms. For example, there are dual new listings of multimedia in the 1971 Addendum ; Barnhart gives a 1969 citation for each. Fortunately, OED gives a 1962 citation for the adjective ; a 1971 one, for the noun. Multihull appears in Webster's 1971 Addendum as an adjective; Barnhart cites a 1971 passage for the noun form only. As $O E D$ gives a 1956 citation for multihulled, preceding its adjective multihull in 1972, this could be an instance of apocope and thus outside our scope. Other pairs such as absurdist and psychedelic, which, when we cannot know whether one shifted from the other, naggingly suggest that Webster's may have labeled as adjectives some modifying nouns appearing prenominally. Since 6000 Words is not intended as a historical guide, any such lapse can mislead scholars.

Webster's sparingly employs the admittedly slippery term slang as the chief indication of language variety, especially so in regard to the derived adjectives. Bombed is labeled slang ; but none of the productive $-y$ set is so marked. Thus we have dicey, kooky, zingy, and ballsy, of which the last may seem vulgar to some people. Unfortunately, the linguistically defensible practice of severely restricting the use of social labels means that Webster's is of lesser use to sociolinguists when no source is given (as from Reader's Digest vs. Atlantic).

Twenty-eight of the 69 derived verbs relate to science and technology; words like allotransplant and lysogenize are unlikely to move into general usage. Yet several have the -ize that terminates 25 of the 69 , or the -ate that terminates another 11. These figures are not true indicators of recent productivity, since the suffix was usually already part of a larger form that is then prefixed, as in the new deacylate (de-acylate). However, there are 16 instances of -ize in the type containerize, which includes all the new verbs constructed by means of a suffix except for the usually productive -en in limpen. The prefixes are more numerous, with de- added to 27 existing verbs like intoxicate, re- to 6 like program, and pre- to 5 like soak. No other prefix has more than 2 occurrences. Demothball shows the earlier functionally shifted verb serving as a root, and deselect is interesting for its euphemistic meaning «dismiss from a training program». 
When there are variant forms, the prefix is attached to both, as in desalinize or desalinate.

Finally, we turn to the 1365 compounds. There are 1166 nouns, 131 adjectives, 43 verbs, 6 adverbs, the interjection right on (which joins zap an the Italian ciao as the only interjections in the book), and 18 unlabeled nouns. The 18 are composed of Noun + Prepositional Phrase as in point of no return, continuing the practice of $W 3$ of not lumping them in the same form class as compound nouns, most of which can be inflected and modified. Thus unexploded letter bombs, but not *name of the football games. All 6 adverbs employ an initial directional preposition except one-on-one. The 5 can be analyzed as prepositional phrases which have become new compounds, upfield joining the old football downfield as one example. But if we derive them that way, there is a deletion of the medial the to produce downrange.

Nineteen of the 43 verb compounds contain a preposition. None appears more than twice except in the 7 terminal occurrences of out as in dry out \& detoxify 》. All combine with common monosyllabic verbs except in bottom out, underachieve, and upvalue. Some have already become roots, as in the subentries underachiever and underachievement; skinny-dip gives -er and -ing forms. Rip-off, which is new in 6000 Words and carries a 1970 citation in Barnhart, has gained wide currency. Paper-train also has interesting implications, in that «the training of dogs » now has a verb entry, wheras litter-train for kittens is not yet in. It is syntactically similar to 17 other Noun + Verb types like bottled-feed and bodysurf. The remaining 5 verbs are Adjective + Noun, where the adjective is a high-frequency monosyllable as in bad-mouth and lowball.

It is in the 131 adjective compounds that the new words show the greatest syntactic creativity. Prepositions appear in 24 items, most in 2 general syntactic groups. Twelve are essentially prepositional phrases as in on-line, with 2 retaining the article as in off-the-rack. Six have an initial verb as in drive-up, with only spaced-out inflected. Three have an initial adjective or adverb as in right-on. Then there are off-putting, uptight, and hands-on.

Sixty-one other adjectives comprise 4 general groups. A terminal noun is in 27 , often in a simple modifying relationship as in open-circuit and redbrick, all with common adjectives and with only 3 inflections - in best efforts, floating point, and mixed-media. There is a second adjective in 4, as in normal orthagonal. A Verb + -ed follows 7, as in well-formed. A noun precedes the adjective in 23. Sixteen of these are scientific terms like radioprotective; 7 are more general terms like creditworthy, which can be derived from a deep structure like worthy of credit.

Seven other sometimes loose groups account for 44 adjectives. Ten are of the type knee-jerk. Five are nouns conjoined by and as in country and western. Thirteen have a terminal inflected verb as in card-carrying or tax-sheltered. We find a verb and another form class in 5, as in hang-loose and pop-top, with only laid-back inflected. There are 5 syntactically ambiguous structures of Adverb + Adjective, as in topologically equivalent. A "group » of 4 contains 
no, as in no-fault, with the only medial in go-no-go. Two are of the type point-of-sale.

Last, there are do-it-yourself (OED, 1845 syntactic citation : 1952 hyphenated form in Time) and peek-a-boo, which differ greatly from the many traditional types like hard-core and planeside. A generative-transformational investigation of the adjective compound shows that some of the more unfamiliar structural types are near-sentences which have been pressed into service as an adjective. Do-it-yourself retains the verb, and go-no-go implies a retrievable do in « go; do not go ». Peek-a-boo « document retrieval where desired documents are identified by light shining through matching holes in index cards $\$$ not only contains verb, but reminds us of the game for amusing a baby. From another point of view we might analyze the item as a functional shift from the noun. The and quintet could be transformationally derived through conjunction and adjectival embedding, where something like "mom has a store -a store sells candy ; pop has a store -a store sells candy » can give the cited « a mom-andpop candy store ». The British home and dry «safe» (OED, 1930 ; Barnhart, 1970 ) is distantly similar, being roughly equivalent to the baseball image in Webster's home free. The Adjective + Noun straight-arrow may derive ultimately from the cliche straight as an arrow. We will not elaborate upon the etymological problems posed by some of the adjectives, beyond saying that the original source of items like major-medical is perhaps unresolvable until we know more dates. It is an adjective in 1965. Barnhart gives a 1965 citation for the noun, with no adjectival entry ; $O E D$ has no listing.

The 1166 noun compounds, comprising almost $24 \%$ of all main entries in 6000 Words, are so numerous as to constitute almost a separate topic. Yet in some ways they are syntactically simpler than the 131 adjective compounds. Thus we find 638 fairly straightforward Noun + Noun types as in access time and zip code, which could be devided into many subgroups on Robert Lees's model in The Grammar of English Nominalizations (1963). The group includes items like Black English with the linguistically untenable definition the nonstandard dialect of English held to be spoken by a majority of American blacks $\gg$, and 4 «soul » words like soul brother. Though blacks have written extensively in informal English since the early 1960's, Webster's reading program which collected their terms was obviously weak to have collected so few. Another 34 items are Noun + Verb +- ing as in data processing and revenue sharing.

The second largest general group is Adjective + Noun. First, there are 277 items like abscisic acid and beautiful people. The uninformed will find the latter and numerous other items like deep structure and general term syntactically ambiguous. Three other groups are essentially Adjective + Noun. Twenty-nine items employ a verb and -ing as in answering service and matching funds. Another 20 have a verb and -ed as in cleft sentence and programmed instruction, to which we might add saturated diving, a unique item containing 2 inflections. Eight items employ the possessive as in chef's salad.

Prepositions occur in 39 simple items. Thirteen have an initial preposition as in downtick, with 5 having a terminal verb as in underkill, instead of a noun. 
There are 4 over-, 3 under-, and 4 others. The 26 terminals have initial verbs in all but 3 as in drop-in and splashdown. The trio are diner-out (with an infixed plural), end around, and sick-out (with a regular plural). There are 8 -out, 6 -off, 4 -in, 2 -down, and 6 others with single occurrences.

Seventeen other items are also composed of rather common forms primarily of two morphemes. The clearest group is perhaps the 6 Verb + Noun types as in pull date and think tank. Slap shot, stuff shot, and slam dunk compose a semantic group. We find at least one verb in pass-fail, flash-forward, and skinny-dip. Then there are cloud nine (presumably with a medial number deleted, from Dante's ninth heaven), one-liner, well-ordering, no-no, and no-tillage.

Though some of the latter items are syntactically unique among the noun compounds in $6000 \mathrm{Words}$, the remaining 102 are syntactically the most complicated. Seventy-seven words have an embedded compound preceding a one-noun headword. Of these, twenty-five are of the type big bang theory, with double modification in a twenty-sixth, quasi-stellar radio source. Twenty-seven are of the type day-care center, with another 7 related items - tow-away zone, trickledown theory, morning-after pill, read-only memory, right-to-work law, surfaceto-air missile, and end-of-day glass. A third «group 》 has 17 items, with 4 like battered child syndrome, 2 like declining-balance method, 2 like one-tailed test, 3 like value-added tax, 2 like thyroid-stimulating hormone (and so an indefinite number of plant $X$-stimulating hormone items), and 4 like alpha-adrenergic receptor.

In 27 items the headword is a compound. Thus we find 2 like community antenna television, 3 like fractional orbital bombardment system and 9 like rapid eye movement, 3 like imported fire ant, 3 like initial teaching alphabet, 4 like modified American plan, 2 like relative biological effectiveness, and citrus red mite.

Finally, there are 2 items with and as in nuts and bolts, and an apocated and in an item that is almost a blend, rockabilly (rock and roll + hillbilly). Two are near-sentences, shoot-'em-up and do-it-yourselfer. The last item is one-on-one.

A comparison of the forms of noun compounds in the Addenda Sections with those in 6000 Words reveals inconclusive, little change. We find arc-jet engine in 1971, whereas in 1976, though the full form remains, there is the synonymous main-entry noun arc-jet. In 1966 the main entry is conservation of baryon number, which is simplified to baryon number in 1976. However, the dual fund of 1971 expands to dual-purpose fund in 1976. Both chairperson and chairone are new in 1976, though Barnhart has a 1971 citation for the former ; $O E D$ lists neither. Webster's enters litmus test «figurative litmus test in 1976. Barnhart gives a 1970 citation; OED Supplement, a 1957 «cultural litmus test $\gg$ one. $W 2, W 3$, and $O E D$ do not list this old attributive compound. Wheeler-dealer is entered in 1966 ; Barnhart provides a 1968 citation for the -ing form only. The item is an alteration of wheel and deal. A final interesting pair are division sign and times sign, both new in 1976 though they are old terms. 
Subtraction sign is in W2. Can the addition and multiplication ones be far behind, in this age of reading?

If the widen our horizons to include all initial free forms in the new words in 6000 Words, we find the following frequencies ; 18 black; 14 air; 13 radio; 11 hard and up; 10 linear and off; 9 open and under; 8 moon, new, point, and self ; 7 double, free, in, power, soft, and time; 6 body, brown, high, no, soul, and space; and 5 blue, central, field, heat, light, and work. Even out of context at least 10 of these relate to science and technology, and actually up to half of the items employing these 31 free forms are technical terms. But the semantic aspects must be reserved for another paper.

In summary, we have observed the syntactic creativity of the new derivations and compounds, especially among the adjectives, some of which may be syntactically unique in a spirit perhaps unparalleled since Chaucer's time. Even if we exclude the 16 proper nouns of nationality that have been incorporated into the body of $W 3$, the 175 proper-noun derivations, the 79 items dropped since the 1966 and 1971 Addenda Sections, and the 48 combinations from abbreviations or initialisms, all of which are technically within our corpus, we find 1443 affixations, or about $30 \%$ of the main entries, in 6000 Words. There are also 1365 compounds, or almost $28 \%$, so that these two processes account for almost $58 \%$ of all new entries. If we exclude the meanings, the figure rises to $70 \%$ of all the new words.

Not only do we find intense productivity among primarily Latin and Greek affixes borrowed centuries ago, but also there is such rising utility among other usual morphemes that numbers of new combining forms have developed. Derivations composed purely of bound forms account for only 289 items, which still exceed the 249 borrowings. The items containing at least one free form show the greatest dynamism. Nouns are by far the most numerous form class, with adjectives trailing behind, and verbs even further with only 115 items. In short, the word-stock of English is now rich enough to accommodate the majority of the new meanings and words required for the language to remain adequate for its speakers in a literate, technological society that is rapidly changing. This change in the historical development of English, which makes it again more of a compounding language like its sister, German, poses challenging and important questions for historical linguistics as the new words of other languages are etymologized, and for lexicographic science, which must collect and record them, particularly in English once the Supplements of the $O E D$ covering the letters $O-Z$ are completed. Then when these lexical items are added to the perhaps 9000 total in 6000 Words and Barnhart, and once enough decades have elapsed so that we can be more certain as to which items have survived, we can more confidently apply historical principles in our analysis of the many new items, perhaps even make tentative formulations as to survivability forces which operate upon each new lexical item, and advance beyond vague theoretical speculating as to what constitutes a «new word $\gg$ and what constitutes a dictionary entry. 